\title{
COMPLAINTS AND COMPLAINT PROCEDURES IN THE EIGHTEENTH- AND EARLY NINETEENTH- CENTURY PROVINCIAL HOSPITALS IN ENGLAND
}

\author{
by
}

\section{W. B. HOWIE*}

THE EMPHASIS in recent years upon complaints and complaint procedures in the Health Service might well give rise to an assumption that a concern about complaints, and ease of access to a complaints procedure, is a product of current notions of patient rights, and contemporary attitudes to health care. Nothing could be further from the truth. From the beginning of the hospital movement it was appreciated that there was a need for a system through which complaints could be made and wrongs redressed. The eighteenth-century gentlemen who founded and managed the early hospitals were too worldly-wise to be unaware of the need for such a thing. The inmates of a hospital ward, confined there for long periods of time, were highly vulnerable, and wholly at the mercy of those who cared for them. Joseph Wilde, who was a patient in the Devon and Exeter Hospital in 1809, recorded, in an account of his stay there, the misery the nurses inflicted upon those at their mercy. ${ }^{1}$ The nurse who cared for him was a "fury", and those who offended her suffered for it. ${ }^{2}$

On the other hand, patients might be guilty of equal impropriety. Wilde, for example, warned those patients allowed out on pass to visit friends in Exeter of the danger of being tempted to indulge in excessive conviviality, and of returning to the hospital in a state of drunkenness. Such incidents were not unknown, and the disturbance in the hospital could be considerable. ${ }^{3}$

Apart from those directly involved in the care of the patient, others might fail in their trust; the food might be bad, the hospital dirty, or the porter negligent. All these things required to be carefully watched, and complaints from patients or staff had to be conscientiously investigated to ensure that no abuse went undetected, no ill deed unpunished. To the attainment of these ends the eighteenth-century hospital managers devoted considerable time and energy, and hospital minute books abound with entries exhorting, reprimanding, or dismissing those who did not achieve, or who did not maintain, the expected standards of behaviour and care.

\footnotetext{
*William Bruce Howie, F.F.C.M., M.R.C.P.(Ed.), D.C.H., D.P.A., 23 Carden Place, Aberdeen ABI IUQ.

1 Joseph Wilde, The hospital a poem in three books written in the Devon and Exeter Hospital in 1809. Norwich, Stevenson, Matchett \& Stevenson, 1810, Book 3 1. 166-167.

2 Ibid., Book 31 . 195-203.

${ }^{3}$ Ibid., Book 2 1. 178-184.
} 


\section{W. B. Howie}

\section{RIGHTS AND DUTIES}

The founders of the eighteenth-century hospitals were quite clear in their intentions. They were setting up hospitals to care for the labouring poor who did not qualify for the workhouse, but who, when sick, required medicines and medical care to recover from their illnesses. By such care, the deserving poor were protected from the trickery of quacks who would deprive them of their money, and by the preservation of their lives the nation benefited; for people meant wealth. ${ }^{4}$

In addition to the primary intention, however, there was also a secondary purpose, related not to health but to morality. Every effort was to be made by the hospitals "to preserve the strictest Regularity of Manners, and due sense of Religion amongst the Patients whilst they are in Hospital". 'In this way each patient would come out of the hospital "a much better Man in Morals as well as in Health, than he went in". "To achieve these objectives it was necessary to provide not only a warm building, good food, and skilled medical and nursing care, but also to enforce a standard of behaviour among all the inmates, patients and staff, which conformed to contemporary concepts of morality.

That it was the intention of the managers to maintain good standards of care and behaviour had to be made clear not only to staff and patients, but also to those charitable members of the public upon whose subscriptions and benefactions the survival of the institution depended. To this end the managers published "Statutes", setting out the organization of the hospital, the duties of the various members of staff, the rules governing patients, and the discipline maintained. For the instruction of various groups within the hospital, these were reinforced by more detailed instructions. The rules governing the behaviour of patients were generally hung in the wards, and read to the nurses, patients, and servants weekly. It was so at Winchester, the model for most of the early infirmaries, ${ }^{7}$ and in the Salop Infirmary at Shrewsbury the "Rules for In-patients" were not only hung up on the walls of the wards and publicly read once a week, "or oftener if it was judged expedient", but in addition were read to all patients on admission. ${ }^{8}$

The Salop "Rules for In-patients" were divided into two parts, the first headed "What the Patient may Expect", and the second "What the Charity Requires". The order is interesting; the patient's rights were detailed first. "What the Patient may Expect" is expressed clearly and succinctly in seven short paragraphs. The patients were assured of the greatest civility and attention from the house surgeon, the matron, the nurses, and every other person employed by the charity, together with regular attendance from the physicians, the surgeons, and the house surgeon. They were informed that the latter would visit them morning and evening so that they could consult

4 collection of papers relating to the County Hospital for sick and lame \&c. at Winchester, London, J. \& J. Pemberton, 1737, pp. vii, 6.

'An account of the Devon and Exeter Hospital which is proposed to be erected on the plan of the County Hospital at Winchester and supported by voluntary contributions, Exeter, 1741, p. 2.

- Thomas Broughton, The perfection of the Christian morality asserted: a sermon preach'd in the Parish Church of St. James in Bristol March 191752, London, J. \& R. Tonson \& S. Draper, 1752, p. 17.

'The orders and constitution of the governors of the County Hospital for sick and lame \&c. at Winchester, Winchester, 1736, Rule XXXIII, and Section IX: Rules to be observed by in-patients, Rule 7.

Records of the Royal Salop Infirmary Shrewsbury, Minutes of Weekly Board, 24 October 1772. 


\section{Complaints and complaint procedures in the eighteenth-and early nineteenth-century provincial hospitals in England}

him about their disorders, and they could send for him at any time if they considered it necessary. They were assured of a clean bed, good food, and adequate meals. If they considered the allowance of food or fluid insufficient, they could obtain more by mentioning the matter to their physician or surgeon, who would order extra rations for them if he thought it proper. The whole was summed up in the final paragraph: "It is the intention of this Charity, that you should have every comfort that your situation can reasonably require."'

For his part, the patient was expected to behave in an orderly way, neither to swear, curse, behave rudely or indecently, play at cards or dice or any other game, to smoke within doors or without unless by leave of the medical staff, nor to obtain any provisions or liquor of any kind other than that provided by the charity. They were required to avoid damaging or wasting the smallest matter belonging to the charity; to assist, so far as they were able, in the work of the infirmary, and punctually to observe the directions of the physicians or surgeons attending them, the house surgeon, the matron, and the nurses. If able to do so, they were to attend prayers daily, and, if they obtained leave from the house surgeon, to attend one of the churches in town on a Sunday, returning to the infirmary as soon as the service was over. Finally, they were warned that "such of you as do not exactly conform to these Rules will have the great Disgrace of being discharged for Irregularity; and being so discharged, you can never be admitted again, by any Recommendation whatsoever". ${ }^{10}$

The rules for the various members of staff reinforced the assurances given to patients as to how they were to be treated. The matron was instructed to treat them with good nature and civility, and was never to permit any degree of cruelty, insolence, or neglect in the servants towards the patients to pass unnoticed. In case of any improper behaviour on the part of the servants, or the patients, she was to draw the matter to the attention of the Weekly Board. The nurses were directed that they should not "neglect, insult, or quarrel with any Patient, on any pretence whatever". If, however, the patients did not observe the rules hung up in each ward, the nurses were under an obligation to draw this to the attention of the appropriate authority.

At the end of this section in the "Rules for In-patients", the patients were informed that if they did not obtain the care set out in that section, or had any other cause to be dissatisfied, they had a right to complain, so that their grievances, if reasonable, could be redressed. To deal with such complaints from patients, and those that arose from staff, a formal complaints procedure had to be established. In main essentials, administrative forms and procedures were remarkably uniform throughout the eighteenth-century foundations, and the method of dealing with complaints was, therefore, very similar in all the provincial hospitals.

\section{PROCEDURES FOR DEALING WITH COMPLAINTS}

In most hospitals, responsibility for the initial investigation of complaints lay with the house visitors, two contributors appointed each week by the weekly meeting of contributors, usually called the Weekly Board, to visit the "House" throughout the ensuing week. The method of election of those appointed varied. At some hospitals -

'Statutes of the Salop Infirmary, Shrewsbury, J. \& W. Eddowes, 1792, 3rd ed., Rules for in-patients.

10 Ibid., Rules for in-patients. 


\section{W. B. Howie}

for example the Manchester Infirmary and the General Hospital at Nottingham - the visitors were appointed in the order in which they stood in the alphabetical list of contributors, ${ }^{11}$ while at others, the visitors were selected only from those showing an active interest in the work of the charity. At Winchester it was specified that no contributor should be appointed as visitor for more than one week in any one quarter of the year, ${ }^{12}$ but as a rule no limitation of this kind was laid down. At Nottingham, the house visitors carried white wands in their hands as they walked through the wards to emphasize the importance of the office.

The responsibilities laid upon the house visitors varied. In general, they were required to ensure that the rules established by the trustees for the conduct of the hospital were duly observed, that the patients or servants had not been guilty of any misconduct, that the food was good, that no food was carried into, or out of, the hospital, and that the patients were not neglected..$^{13}$ At Winchester it was expressly laid down that the house visitors should enquire whether the patients had been "well and orderly attended" by the physicians, surgeons, and apothecary, as well as by nurses and servants. ${ }^{14}$ At the Devon and Exeter Hospital, the matters into which the house visitors were to enquire were set out in sixteen points that probed in detail into the behaviour of the physicians, surgeons, matron, nurses, domestics, porters, and patients. ${ }^{15}$ Generally the rules required that when the house visitors entered a ward all the servants of the house withdrew, while the patients stood by their respective beds. ${ }^{16}$

The action taken by the house visitors when they received complaints from either staff or patients varied according to the seriousness of the matter. The normal procedure was to enter the complaint in a book provided for the purpose, and report it to their parent body, the Weekly Board, where it was further enquired into, and the appropriate action determined. From time to time the house visitors acted on their own initiative, but, as a rule, only when delay would be harmful. At a meeting of the Weekly Board of the Salop Infirmary in 1783, the house visitors reported that on the previous Wednesday they had discharged the nurse on the women's ward at the request of one of the surgeons "for imprudently administering an Opiate to one of the Patients without any Direction from the Physician or Surgeon under whose Care she was". 17

The investigative procedures adopted by the Weekly Boards were normally simple and informal. Those concerned were summoned before the Board and questioned.

\footnotetext{
"William Brockbank, Portrait of a hospital, London, Heinemann, 1952, p. 203. Frank H. Jacob, $A$ history of the General Hospital near Nottingham, Bristol, John Wright, 1951, p. 51.

${ }^{12}$ The orders and constitution of the governors of the County Hospital for sick and lame \&c. at Winchester, Winchester, 1736, Section II: Rules and orders concerning the government and conduct of the house, no. 1 .

${ }_{13}$ S. T. Anning, The General Infirmary at Leeds, Edinburgh, Livingstone, 1963, 2 vols., vol. 1, p. 91.

14 The orders and constitution of the governors of the County Hospital for sick and lame \&c. at Winchester, Winchester, 1736, Section II: Rules and orders concerning the government and conduct of the house, no. 2 (3).

${ }^{15}$ Statutes and constitution of the Devon and Exeter Hospital with the rules and orders for the government and conduct of the house, Exeter, Andrew Brice, 1764, Rules for house visitors.

${ }^{16}$ Statutes of the Salop Infirmary, Shrewsbury, J. \& W. Eddowes, 1792, 3rd ed., Rules for house visitors, Rule 115.

${ }^{17}$ Minutes of Salop Weekly Board, 4 October 1783.
} 


\section{Complaints and complaint procedures in the eighteenth-and early nineteenth-century provincial hospitals in England}

Generally, only the complaint, the findings upon it, and the outcome were recorded in the Minutes of the Board. Occasionally, however, the procedure was more formal. In April $1798 \mathrm{Mr}$. Woody, the house surgeon, wrote to the directors of the Salop Infirmary stating that he was informed that reports were in circulation in Shrewsbury accusing him of disseminating irreligious and republican principles and books amongst the patients at the infirmary. He requested that the directors should "investigate the charges in the most scrupulous manner". This the directors proceeded to do by questioning each member of staff in turn - from the secretary and matron to the porter - and recording their answers in the Minute Book. By the end of the investigation Mr. Woody was totally exonerated. ${ }^{18}$ Upon another occasion, when a matron was accused of dishonesty - amongst other activities, skimming the milk and selling the cream - the directors of the Salop Infirmary questioned not only the staff, but also a number of tradesmen and their wives, under oath, requiring them to sign with their names or their mark the entries recording their evidence. The evidence accumulated was made available to the matron, and she was asked for her observations upon it. She replied by letter and requested that further witnesses be examined. This was duly done, and the matron again asked if she had any further evidence to produce. On replying that she had not, it was unanimously decided that she had been guilty of defrauding the charity. A motion that she be dismissed was carried, and the secretary was directed to inform her that she should leave the infirmary within one week.

The formality adopted upon this occasion was, perhaps, related to the fact that a prosecution might have resulted. The directors were, however, dissuaded from litigation by their attorney, on the grounds that the money lost could be witheld from the salary due to the matron. This would be less costly than a prosecution. ${ }^{19}$ In 1802 , the house surgeon and the house pupil arrested a man carrying away eight to nine pounds of lead from a water-pipe at the front of the building. As it was assize week, the clerk of the peace advised the directors to prosecute. The man was fined one shilling, and sentenced to one year in the house of correction, but the clerk of the peace presented the Infirmary with a bill for $£ 517 s .6 d$., which "considerably exceeded every idea that the Directors had formed of such a prosecution".20 Three years later, when the same house surgeon found a patient stealing five loaves from the bakehouse, the directors decided merely to discharge the patient rather than bear the expense of a prosecution for felony. ${ }^{21}$

In dealing with complaints, the Weekly Boards were by no means unthinking bodies, merely confirming the views of the house visitors. At the Salop Infirmary, in June 1781, three members of the medical staff - two surgeons and one physician made an entry in the visiting book stating that the patients in both the men's and the women's wards had complained of the badness of the milk porridge; that the cook on being informed of the complaint was very impertinent, saying that "they should have it worse"; and that upon enquiry they had found the complaint just. The two house

\footnotetext{
${ }^{18}$ Ibid., 28 April 1798.

19 Ibid., I March 1806, 8 March 1806, 15 March 1806, 29 March 1806.

20 Ibid., 21 August 1802.

${ }^{21}$ Ibid., 13 April 1805.
} 


\section{W. B. Howie}

visitors of the week confirmed the complaint, and added that several patients had represented to them that the vegetables also were "very indifferent". The Weekly Board examined the cook and the matron, and accepted their explanation that the porridge was less good than usual partly because of a scarcity of good cereals, and partly because of its being put into unwashed cups, the nurses having frequently neglected to see that they were properly cleaned before being sent down to the kitchen. On the charge of impertinence, the cook claimed she was much provoked, and by the remark that the patients would be the worse for their complaint had only meant that "she would in future endeavour to abridge them of the ill bestowed Indulgence lately shown them respecting the Quality of it, by reducing it to a Degree more suitable to the Intention, and more conformable to the established Usage of the House". Upon the complaint concerning the vegetables, the trustees decided that they were as good as the season and market allowed. As a result the "ungrateful conduct of the Complainers was duly reprimanded", and the ringleader discharged "as an unworthy object of this Charity". ${ }^{22}$

In some hospitals the Weekly Board took a more active part in the early stages of the complaint procedure. At the Devon and Exeter Hospital, the Weekly Board was required to make a "general visitation" of the patients and servants once a quarter, that of the patients taking place on the week before the Quarterly Court of Governors, and that of the servants in the week following. ${ }^{23}$ The minutes of the Weekly Board duly record these visitations, the committee going into every ward and enquiring from the patients whether they had any complaints "concerning the Attendance given them, and their Usage from the Physicians, Surgeons, A pothecary \&c". Out-patients were summoned to the board room, and questioned in the same way about their health and the care taken of them by the medical staff. ${ }^{24}$

Complaints about care did not always arise from patients in the hospital or from members of staff. This was particularly so in relation to complaints about medical staff. On occasion, patients wrote to the trustees after they had been discharged, complaining of the treatment they had received, or sought the support of some influential contributor to the charity, very often the subscriber or benefactor who had recommended them for admission. At times, complaint was made by those governing some other institution such as a house of industry, or by a practitioner who was not on the staff of the hospital. Where another practitioner was concerned, this often led to public controversy. In 1805, a woman was admitted to the Bristol Infirmary from the local Bridewell with a condition that required operation. This she refused, and asked instead to be discharged. After permission for discharge had been obtained from the keeper of the Bridewell she was allowed to go; whereupon her own practitioner published a lengthy pamphlet alleging that the woman would have undergone surgery if he had been allowed to be present, that she had been "threatened with Bridewell" if she did not submit, and that as a result of her period in the infirmary "her life hath

\footnotetext{
22 Ibid., 16 June 1781.

${ }^{23}$ Statutes and constitution of the Devon and Exeter Hospital, op. cit., note 15 above. 22nd Statute.

${ }^{24}$ Records of the Royal Devon and Exeter Hospital, Minutes of Weekly Committee of Board of Governors, 23 October 1747.
} 


\section{Complaints and complaint procedures in the eighteenth-and early nineteenth-century provincial hospitals in England}

been in most monumental danger, her sufferings have been protracted, and her future existence probably embittered". A special committee of forty members was set up to investigate the complaint, and the surgeons of the hospital were acquitted of all the charges by thirty-seven votes to three. This did not, however, prevent an extensive debate in the Bristol newspapers. An interesting point that emerged during the enquiry was that the eight house visitors who attended the infirmary during the period in which the woman had been an in-patient were prepared to declare upon oath that it was their custom to accompany the surgeons when they visited their patients, that they had seen the woman daily, and that they had never heard her express any wish to see the complaining practitioner, or seek permission for him to be present at an operation. ${ }^{25}$ While this devotion to duty showed interest in the work of the infirmary, it negated the purpose of their appointment, since it would be virtually impossible for any patient to make a complaint about the care he was receiving in the presence of those providing it. The requirement in other hospitals that the staff withdraw from the wards when the house visitors entered the ward was clearly more effective.

Even when this was done, however, there was a difficulty still remaining. The timid patient dependent upon the care and good opinion of those in authority might well find it difficult to draw attention to some misdeed while still in the hospital. For this kind of problem there was a further procedure built into the system. On discharge from hospital, each patient had to appear before the Weekly Board. This allowed three things to be done: first, the patient to thank the trustees for the care he had received; second, the chairman of the board to deliver an appropriate admonition as to the need to live a good and Christian life; and third, to ensure that the patient had not been subject to any ill treatment or neglect. The procedure adopted at the Salop Infirmary was set out in the Fiftieth Annual Report. "Those who are discharged also appear before the Directors, and (all persons belonging to the House being excluded) they are strictly questioned as to the treatment they have received; so that no instance of neglect or unkindness in the higher department - no attempt to procure from them fee or reward in the lower - may pass undetected." 26 This was the finest mesh in the net of complaints procedure.

\section{TYPES OF COMPLAINT}

Complaints against patients. Not surprisingly, the group against which the greatest number of complaints was levelled was the patients. For the most part they were found guilty of minor infringements of the rules, and provided they showed a reasonable degree of contrition when appearing before the Weekly Board, and were prepared to promise not to repeat the offence, they escaped with an admonition. Indeed, this was so even on an occasion when the house visitors at the Salop Infirmary entered a complaint against all the male patients in one of the wards for spending their time at cards, cursing and swearing, refusing to assist in cleaning the ward, and behaving with great rudeness and insolence to the nurse. They were called before the Board, but on

${ }^{25}$ G. Munro Smith, A history of the Bristol Royal Infirmary, Bristol, J. W. Arrowsmith, 1917, pp. $158-159$.

${ }^{26}$ Rev. Archdeacon Plymley, Fiftieth report of the state of the Salop Infirmary by the auditors, Shrewsbury, 1795. 
promising never to be guilty of any future misconduct, were subject only to a severe reprimand by the chairman "for their scandalous Behaviour". 27

More serious misdemeanours were followed by expulsion. Drunkenness was not a great problem except in those allowed out of the hospital for short periods of time, for considerable care was generally taken to prevent alcohol being brought into any hospital. Indeed, on one occasion at Salop, a patient was discharged, and ordered never to be readmitted - the most severe form of punishment - for having brought into the infirmary half a pint of brandy for the use of a patient previous to his undergoing an amputation..$^{28}$ What might, today, appear a more innocent form of refreshment could lead to equal difficulty. In December 1776, the governors of the Salisbury Infirmary passed a motion to prevent the increase in tea-drinking, and directed that a notice be put in each ward that if such irregularities be continued, contrary to the order of the physicians and surgeons, the offenders would be discharged. ${ }^{29}$ The ban was not raised till $1810 .{ }^{30}$

Unauthorized leave was also generally visited with expulsion, particularly if there was a suggestion of impropriety. In 1802, a drummer in the Shropshire Militia under treatment for venereal disease stayed out all night, having put the ward coalbox under the bedclothes to deceive the nurses. Although the crime merited discharge, the Weekly Board allowed him to remain, provided he acknowledged his error before the other patients, since the house surgeon pointed out that, if discharged, he would be a danger to others. The drummer, however, refused the terms offered, and was discharged the following week. ${ }^{31}$

Any complaint of immoral behaviour in the hospital brought immediate action. At Exeter in 1771 the apothecary reported to the Weekly Committee on some "irregularities" that had been committed by a male patient and a female patient. He had complained to some of the governors who had formed a Special Committee to look into the matter urgently. Convinced that the patients had been guilty of "great Indecencies" the committee ordered that they be forthwith discharged "and (for Example Sake) call'd all the other Patients into the Board-Room to hear the sentence"' ${ }^{32}$ At Salop in 1789 a surgeon complained that one of the venereal patients had been guilty of "repeated Acts of Irregularity tending to retard his Cure" and that, among other crimes, there was reason to suspect that he had had intercourse with a female patient discharged the previous week as a result of being pregnant. The man concerned was ordered to be expelled immediately "and never admitted as an Object of this Charity again upon any Recommendation whatever". ${ }^{33}$

Stealing from the charity, or from fellow-patients, was looked upon as a most serious offence, and brought upon the miscreant a ban on all future admission. As a rule, the thief had left the hospital before the crime was discovered, but at times the

27 Minutes of Salop Weekly Board, 15 June 1774.

28 Ibid., 5 December 1778.

${ }^{29}$ The history of the Salisbury Infirmary founded by Anthony. Lord Feversham A.D. I760. Salisbury. Salisbury and District Infirmary and Hospital League, 1922, p. $9 \mathrm{col} .1$.

30 Ibid., p. 12 col. 2.

${ }^{31}$ Minutes of Salop Weekly Board, 6 November 1802.

32 Minutes of Devon and Exeter Weekly Committee, 10 January 1771.

${ }^{33}$ Minutes of Salop Weekly Board, 26 September 1789. 


\section{Complaints and complaint procedures in the eighteenth-and early nineteenth-century provincial hospitals in England}

hospital authorities felt strongly enough to advertise the crime in the newspapers and seek to bring the thief to justice. The Salop governors advertised in the Shrewsbury Chronicle the theft of a quantity of clothing by Elizabeth Chidley, a venereal patient. Anyone providing information whereby she might be secured and punished was to be duly rewarded. A description of the young woman was provided - she was about twenty-two years of age, of short stature, brown complexion, and black eyes. When she left the hospital she was wearing a red domino, and a black silk hat lined with white silk, both of which she had stolen, along with a shift, a pair of stays, a cotton gown, three caps, a silk handkerchief, a check apron, a pair of stockings, and a pair of shoes. ${ }^{34}$ She evidently got clean away, for there is no report of her being apprehended, lodged in the gaol, or tried at the sessions or assize courts that year. She was more fortunate than Sarah Harrison who, five years later, stole a number of articles of clothing from the patients in the women's ward. The board ordered that she should never be readmitted, but more serious punishment was to follow. She was apprehended, tried at the town sessions, and sentenced "to be publicly whipt at the Infirmary". ${ }^{35}$ Some cases were less serious. In 1746, the weekly visitors at Exeter complained that a patient had given part of his bread allowance to his wife "imagining that it was at his own disposal". Having expressed ignorance and sorrow, and having promised never to do the like again, he was reprimanded, but not discharged. ${ }^{36}$

Complaints by medical staff against patients were always taken very seriously, and the medical staff could themselves take action when this was required. Complaints of insolence to medical staff led to instant discharge, and the ultimate sentence of no longer being eligible for admission. Refusal to accept treatment was a cause for discharge, and if patients discharged themselves against advice, their readmittance was prohibited. In 1783, a woman in the Salop Infirmary refused to take the medicines prescribed for her, and on the same day was discharged for "irregularity" by the surgeon responsible for her care. ${ }^{37} \mathrm{~A}$ venereal patient who refused to be salivated was discharged by the Weekly Board when the refusal was reported to them by his surgeon. ${ }^{38}$ At Exeter, a patient with dropsy, who, after paracentesis, refused to continue to stay in hospital and "obstinately left it" was, by order of the Weekly Board, entered in the books of the hospital as being discharged for gross irregularity, a sentence which denied her any future admission. ${ }^{39}$ At Salop, on the recommendation of the medical staff, any patient who consulted a quack was denied admission or readmission..$^{40}$

But the complaint most frequently made against patients by medical staff was that they were "improper objects" of the charity - that is, that they were receiving care in the hospital when they, or those responsible for them, could afford to pay for it. The medical staff frequently drew attention to the presence of apprentices, and they were

\footnotetext{
34 Shrewsbury Chronicle, 8 November 1777.

${ }^{35}$ Ibid., 19 January 1782.

${ }^{36}$ Minutes of Devon and Exeter Weekly Committee, 20 November 1746.

${ }^{37}$ Minutes of Salop Weekly Board, 2 August 1783.

38 Ibid., 21 March 1767.

${ }^{39}$ Minutes of Devon and Exeter Weekly Committee, 27 September 1744.

${ }^{40}$ Minutes of Salop Weekly Board, 22 October, 1796.
} 


\section{W. B. Howie}

discharged, since, under the standard form of indenture, their masters were held to be responsible for their medical care. ${ }^{41}$

Those who received sick benefits from Friendly Societies were also considered capable of paying for their care, either directly or through the society. During the last forty years of the eighteenth century there was a rapid growth of Friendly Societies throughout the whole country, but even by mid-century they were numerous in the West Country, ${ }^{42}$ and by 1800 there were 194 in Devon alone. ${ }^{43}$ There had even been a brief attempt to set up a voluntary insurance scheme in Devon by private Act of Parliament in 1768. Among other benefits, the scheme had allowed free medical treatment up to $£ 55 s$. $0 d$. per annum, but the venture failed and the Act was repealed three years later. ${ }^{44}$ Against such a background, the medical staff in the Devon and Exeter Hospital were particularly vigilant to draw to the attention of the Weekly Board the presence in the hospital of those who were entitled to sick benefit. In 1776, for example, the Weekly Board ordered that a male patient admitted following an accident be removed from the hospital forthwith unless he paid to the apothecary five shillings out of the six shillings a week he was entitled to receive from the society to which he belonged. ${ }^{45}$ Attempts to secure treatment for club members by contributing a subscription, and then having members treated under subscribers' rights were also rejected by the medical staff and the Weekly Board, the subscription being returned in such cases to the subscriber. ${ }^{46}$

Most often the individual involved in this kind of complaint was someone brought to the hospital following an accident, who subsequently appeared able to pay for treatment. In 1775, for example, one of the physicians reported to the Salop Board that the father of an in-patient was a freeholder possessed of $£ 100$ per annum. The secretary was instructed to write to the father to express the hope that he would satisfy the charity and the surgeon. Two months later the father attended the board and paid $£ 4$ for diet and medicines during the twelve weeks and five days his son had been in hospital, the surgeon declining any fee for his services. ${ }^{47}$ The Devon and Exeter Board took a somewhat stronger line. In 1762, a woman who appeared to be in circumstances which enabled her to pay for her care was discharged as an "improper object" of the charity, and required to pay ten shillings for her fortnight's accommodation; her husband was threatened with a writ if it were not paid. ${ }^{48}$

On occasion the Weekly Boards dealt with complaints of anti-social behaviour where there was no offence against the charity. In 1778 the Salop Weekly Board was informed by the nurse in the male ward that she had received a copy of a "scurrulous and obscene letter" sent by one of the in-patients to his wife "together with a vindication of the poor injured woman's character". The board interviewed the patient

${ }^{41}$ Minutes of Devon and Exeter Weekly Committee, 2 January 1745, 15 January 1761.

${ }^{42}$ P. H. J. H. Gosden, Voluntary associations in nineteenth century Britain, London, Batsford, 1973, pp. $5,9$.

${ }^{43}$ Arthur Warne, Church and society in eighteenth century Devon. Newton Abbot, David \& Charles, 1969, p. 163.

4 Ibid., p. 161.

45 Minutes of Devon and Exeter Weekly Committee, 8 May 1746.

46 Ibid., 15 December 1763.

47 Minutes of Salop Weekly Board, 8 July 1775.

48 Minutes of Devon and Exeter Weekly Committee, 3 June 1762. 


\section{Complaints and complaint procedures in the eighteenth-and early nineteenth-century provincial hospitals in England}

concerned, who explained that as he could neither read nor write he had applied to a fellow-patient to answer a letter he had received from his wife, "and in order to get rid of her importunities desired him to put something bad in it, meaning thereby only to discourage her from sending him any more unwelcome letters". The whole letter when finished had not been read to him so that he did not know all that was in it. The writer acknowledged his involvement and, being reported by the matron and apothecary as unruly, was discharged. The erring husband showed "a proper degree of compunction for his misconduct", and escaped with a severe reprimand. ${ }^{49}$

In 1796 the Salop Board became interested in what must have been one of the earliest examples of hospital involvement in non-accidental injury to children.

The Board having been informed that the accident of a fractured Thigh for which a young boy was brought hither on the 4th instant, was occasioned by the barbarous correction of his own father, one Thomas Price, alias Crack of the Blackmoor, in the parish of Westbury; who without any reasonable provocation on the poor child's part, took him up by the hair of his head, dashed him violently against the ground, and then kicked him repeatedly; that he has since nearly killed one of his daughters aged about 16; and that it is his common practice to beat his wife and children in the most savage manner upon the slightest provocation.

Ordered that the Rev ${ }^{d}$ Edward Leighton, Mr Edward Harris, Mr Jenkins, or some of the Justices in that neighbourhood, be made acquainted with his character and conduct; and that they be earnestly requested by the Board to bring the offender to condign punishment, in order to deter him in future from a repitition of such gross violation of the laws of society and humanity. ${ }^{\circ 0}$

Complaints against nursing staff. Complaints against nursing staff, if less frequent than those made against patients, were a cause of even greater concern to the Weekly Boards, for the behaviour of its nurses influenced the reputation of the charity. As a result, misdemeanours by the nursing staff were treated with greater severity than those of patients. Many complaints concerned personal behaviour, and, if found proven, led to immediate dismissal. At Salop, in 1791, a nurse found to have taken gratuities from patients was instantly discharged for having indulged in such a "shameful practice". ${ }^{1}$ One of the matrons was discharged when the house surgeon reported that she was frequently intoxicated, and that this was becoming known in the town. ${ }^{52}$ Another matron was discharged for "insolently refusing to look at or Obey an order of the Board" when it was delivered to her by the secretary..$^{53}$

Complaints of error or incompetence also led to dismissal. At Salop in 1783, as has already been mentioned, a nurse was discharged for administering a drug without authority. ${ }^{54} \mathrm{~A}$ few years later, one of the physicians complained that the nurse in the female ward had committed several mistakes in dispensing medicines to the patients "through mere Carelessness and Inattention", and that the most recent instance "might have been attended with very disagreeable consequences". After enquiry, the board ordered that she be immediately discharged.ss

Complaints were made from time to time of lack of cleanliness in the wards, and of

\footnotetext{
49 Minutes of Salop Weekly Board, 24 January 1778.

so Ibid., 16 April 1796.

s1 Ibid., 26 March 1791.

52 Ibid., 26 September 1807, 7 November 1807.

s3 Ibid., 21 April 1798.

s4 Ibid., 4 October 1783.

ss Ibid., I May 1790.
} 


\section{W. B. Howie}

the offensive nature of many of them. In November 1789, the weekly visitors at Salop reported to the board that they had found the men's ward very offensive at four o'clock the previous afternoon. The nurse attributed this "to a great Number of bad chirurgical Cases now in the Wards, and the Perverseness of some of the Patients in drawing down the Window sashes whenever they are put open for the Circulation of fresh Air". ${ }^{36}$ A year before, the visitors had made the same complaint; that the wards were dirty and the windows shut. The nurse maintained that she opened the windows every morning, but that the patients shut them because they could not stand the cold. The wards were offensive, she said, because of the kind of case in them, and the overcrowding. ${ }^{57}$ Conditions in the eighteenth-century hospital must, indeed, have been very bad at times, and it is not surprising that odd things occasionaly occurred. In September 1744 the matron of the Devon and Exeter complained that on the previous Monday all the nurses had left the hospital without her leave, and had absented themselves for three hours. The porter had been sent to order them to return, but they had refused. The board discharged the ringleader in the revolt, and reprimanded the others. ${ }^{38}$

From time to time complaints were made by patients on the treatment received. In 1787, the Salop Weekly Board was handed a letter from a patient discharged from one of the wards, complaining of cruel usage and scurrilous language from the nurse. It was said to have been written on behalf of all the patients in the ward, and to have been heard and approved by them. The complaint was investigated by the house visitors, and found false, all but two patients denying all knowledge of it, the majority saying that the nurse "had always behaved with great tenderness", and that they had never heard any improper language from her. ${ }^{99}$ The complaint was rejected.

Accusations against staff, if they could be proved, were dealt with severely by the Weekly Boards, particularly if the complaint reflected upon the charity. The complainant was equally severely dealt with if the grievance could not be proved, and if the charity might suffer from its having been made. In 1776, a male patient at the Salop Infirmary found guilty of raising and propagating "a slanderous Report respecting the Nurse in the Men's Ward having neglected a patient under her Care who is since Dead", was ordered to be discharged immediately for irregularity, never to be admitted again, and previous to his discharge "to be conducted through the several Wards and the Kitchen and his Crime published to all the Patients and Servants as a means of deterring others hereafter from inventing and propagating false reports of such dangerous tendency". ${ }^{60}$

Complaints against medical staff. Complaints made by patients against senior members of the medical staff were few in number, but it might be thought surprising that they were made at all. In 1762 the Weekly Board at Salop considered a letter from a patient complaining that her physician had prescribed medicines for her "that had been the Death of two persons in nine days". After careful examination by the

\footnotetext{
s6 Ibid., 21 November 1789.

s7 Ibid., 15 November 1788.

s8 Minutes of Devon and Exeter Weekly Committee, 20 September 1744.

39 Minutes of Salop Weekly Board, 18 August 1787.

60 Ibid., 23 March 1776.
} 


\section{Complaints and complaint procedures in the eighteenth-and early nineteenth-century provincial hospitals in England}

Board, she "acknowledged her offence" in making such false statements and agreed to write to the physician concerned "begging his pardon". ${ }^{61}$ Some years later, in a letter to the apothecary, one of the male patients accused the medical staff of neglect. The Weekly Board examined the patient, the surgeons and physicians, the apothecary, and all the nurses who had attended the patient. The conclusion reached was that the accusation was without foundation, and that, on the contrary, the complainant "had been very regularly and tenderly treated". It was ordered that he should never again be admitted to the Infirmary, upon any recommendation whatever. ${ }^{62}$

In September 1797, a man who had been admitted to the Bristol Infirmary with a dislocated elbow five months before, complained to the Weekly Committee "of want of Skill in the Surgeons of the House, and of Mr. Lowe in particular" for having failed to reduce the dislocation. Having enquired into the matter, and examined two other members of the surgical staff who had each attempted reduction without success, the Committee concluded that the complaint was unfounded, and that everything possible had been done to give relief. ${ }^{63}$

Complaints were not always disproved, however. In 1788 two patients at Salop, a man and a woman, complained through the directors of the house of industry that their surgeon, John Dodd, had neglected them. The woman later recanted, saying that she had been intoxicated at the time she made the accusation, and the matter went no further, as Mr. Dodd was from home. ${ }^{64}$ Some time later, however, the directors of the house of industry wrote again to the Weekly Board complaining that, as a result of Mr. Dodd's treatment, a former patient was now a burden upon the parish, together with his wife who was lying-in, and his six children. While an in-patient with an injured leg, the man had complained to the house visitor of neglect, Mr. Dodd not having seen him for twelve days. On hearing of this, Mr. Dodd had sworn at him, said his "leg should rot off", and discontinued his kitchen diet and allowance of ale. Being "uneasy" the man had left the infirmary, but his leg was in such a state that he was incapable of maintaining himself, and he and his family had required admission to the house of industry. In view of the seriousness of the complaint, it was referred by the Weekly Board to a Quarterly General Board of Governors, and a copy sent to Mr. Dodd. ${ }^{65}$ On the day of the meeting, Mr. Dodd sent a message that he had had to go out of town on urgent business and could not attend. The Board, however, decided to consider the matter in his absence, and concluded that the man had indeed been neglected, as had several other patients who had made similar complaints. At the end of the meeting, the governors wrote to Mr. Dodd indicating that since his other duties appeared to render it inconvenient for him to give proper attendance to the patients in the house, they thought it appropriate "to dispense with his Attendance in future as a Surgeon to this Infirmary".66 John Dodd was subsequently re-elected, but only after he had apologized for his inattention to the patients, and promised "an assiduous

\footnotetext{
${ }^{61}$ Ibid., 28 August 1762.

62 Ibid., 17 May 1777.

${ }^{63}$ Records of Bristol Royal Infirmary, Minutes of Weekly Committee, 6 September 1797.

64 Minutes of Salop Weekly Board, 5 April 1788.

65 Ibid., 29 January 1791.

${ }_{66}$ Minutes of Quarterly General Board of the Salop Infirmary, I February 1791.
} 


\section{W. B. Howie}

Attendance for the future". ${ }^{67}$

It was, perhaps, such rough and arrogant treatment by medical staff that led Thomas Percival to include in his system of medical ethics a section on professional conduct in hospitals and other medical charities. The raison d'être of Percival's work - which was first printed privately in 1794 - was disagreement and quarrels within the profession in Manchester, but his study of this issue inevitably led to consideration of the wider issues of the doctor and patient relationship. Percival required a high standard of care. Hospital physicians and surgeons were to minister to the sick "with due impression of the importance of their office, reflecting that the ease, the health and the lives of those committed to their charge depend on their skill, attention and fidelity. They should study, also, in their department, so to unite tenderness with steadiness, and condescension with authority as to inspire the minds of their patients with gratitude, respect and confidence". The feelings and emotions of patients were to be considered no less carefully than the symptoms of their diseases. Patients were to be questioned about their illnesses in a tone of voice that could not be overheard. Secrecy was to be strictly observed. Women were to be treated with great delicacy; "to neglect or sport with their feelings is cruelty". Fear of a form of treatment, for example venesection, was, in Percival's view, a contra-indication to its use. "Even the prejudices of the sick are not to be condemned or opposed with harshness. For though silenced by authority, they will operate secretly and forcibly on the mind, creating fear, anxiety and watchfulness." 68

The basic concept of the need for kindness and care towards the sick-poor was not new, it had been advocated much earlier in the century by many boards of trustees for example, by the Salop Infirmary in its statement of what the patient might expect - and by preachers of many anniversary sermons, but the general publication of Percival's code in 1803 gave it renewed impetus. For the idea was now being proposed from within the ranks of the physicians and surgeons themselves, as an acceptable standard of conduct that could be expected from the profession, and its observance gradually became accepted as mandatory.

In one single respect Percival's views had a slightly unfortunate effect, though the original intention was sound. In eighteenth-century terms Percival pointed out that the medical men in every institution were, to some degree, responsible for, and the guardians of, the honour of each other. They ought not to reveal in public, therefore, anything that might injure a colleague's reputation, any such matter that might give rise to complaint being judged only by the medical staff of the institution as a body. Whilst this was very necessary in the context of its time, to counteract the outbreaks of pamphleteering wars between medical men that occurred from time to time throughout the eighteenth century, ${ }^{69}$ the working of this principle in its essential details, has, in later times, led to accusations of a conspiracy of silence by the profession to suppress unpalatable facts.

\footnotetext{
${ }^{67}$ Minutes of Special General Board of the Salop Infirmary, I March 1792.

68 Chauncey D. Leake (editor), Percival's medical ethics, Baltimore, Md., Williams \& Wilkins, $1927, \mathrm{pp}$. $71-73$.

${ }^{69}$ Lester S. King, The medical world of the eighteenth century, Chicago, University of Chicago Press, 1958, pp. 227-253.
} 
On occasion, medical staff broke ethical rules other than professional ones. In March 1770 the apothecary of the Salop Infirmary who, at that time, also occupied the office of secretary, resigned on being invited to settle as apothecary at Ellesmere. ${ }^{70}$ Just after midsummer he died, and demands then began to pour in to the Weekly Board for the payment of money due for drugs delivered to the infirmary over the previous two years. In September it was found that subscriptions to the amount of f25 $4 s$. 0d. had been paid to the apothecary without being made over to the undertreasurer. ${ }^{11}$ For the payment of creditors at a distance, the procedure employed was for the under-treasurer to issue a draft made payable to the secretary, who had the duty of remitting the money to the creditors on their order..$^{72}$ The apothecary, acting as secretary, had not forwarded the money, and, though the trustees endeavoured to contest the largest claim, from a London druggist, the ultimate loss amounted to $£ 182$.

Complaints about food. Food was the most frequent cause of patients' complaints, the quality of the bread, the beer, and the ale being most commonly cited. Complaints had, however, to be carefully worded. Six women patients at Salop were brought before the Board by the house visitors "for contemptuously saying that the meat Stank and refusing to eat it". In the view of the visitors this complaint was unfounded, and they were required to beg the pardon of the matron, and promise good behaviour in future on pain of being discharged. To complete their disgrace, a copy of the minute was posted up in each ward. ${ }^{73}$

Such complaints were not always rejected, however. In 1777 the quality of the small beer was criticized at Salop. The Weekly Board agreed that it was very bad, and considered that this was due to the fact that it was brewed by a woman who kept pigs. The matron was directed to end the arrangement, and seek some other brewer. ${ }^{74} \mathrm{~A}$ similar complaint two years later about the quality of the ale led to the discovery that it had been the practice for several years past "to brew the ale in the Furnace wherein the Patients' foul sheets and shirts are weekly boiled". The Board decided that to "remove such Inconveniency in the future" an iron furnace be erected in one of the cellars in which, for the future, the ale should be brewed. ${ }^{75}$

\section{EFFECTIVENESS OF THE SYSTEM}

As with all complaints procedures, the system operated in the eighteenth-century hospitals was not infallible. The house visitor had an important part to play - at least at the initial level of complaint - and if he failed to carry out the task assigned to him, one channel through which the patient could make his grievance known to the trustees was lost. This could happen. In 1801 the writer of the Annual report of the General Infirmary at Hull drew the attention of the trustees to the need for "those Gentlemen of the Town who have leisure" to attend the Weekly Board to "avoid the inconveniencies arising" from want of a quorum. This, however, was not the only

${ }^{70}$ Minutes of Salop Weekly Board, 17 March 1770.

"Ibid., 21 September 1770.

"Twenty-fifth report of the state of the Salop Infirmary by the Auditors, Shrewsbury, 1770.

${ }^{73}$ Minutes of Salop Weekly Board, 18 August 1789.

74 Ibid., 15 February 1777.

7s Ibid., 18 December 1779. 


\section{W. B. Howie}

complaint. On occasion those appointed to act as house visitors had failed in their duty to attend the infirmary, a duty which, it was pointed out, "was necessary to the good order of the House". The writer expressed the hope "that every Trustee, who shall in future be summoned as House Visitor, will either execute the office, or acquaint the Secretary that he shall not do it, that another Trustee may be nominated in his place" ${ }^{76}$ While difficulties over attendance at meetings arose in other hospitals from time to time, it is uncommon to find any reference, as at Hull, to failure on the part of the house visitors to attend to their duties. If such a failure did occur, however, it was more likely to do so in those hospitals where house visitors were appointed upon some rota basis than in those which appointed their visitors at a preceding Weekly Board. Those attending the Weekly Board were more likely to be those trustees who had a real interest in the charity.

But even if the house visitors undertook their duty as the rules required, there were still problems that had to be resolved. Joseph Wilde appreciated the intention of the Devon and Exeter Trustees in arranging for the wards to be visited throughout the week by the house visitors, and the attempts made by them to detect abuse.

\footnotetext{
But yet, these visits have not all th'effect

The gen'rous patrons wish; for gratitude

And awe will often check the just complaint

From the full heart, fast rising to the lips."
}

If feelings of gratitude were overcome, it still took considerable resolution to denounce the cruelty of a member of staff. On one occasion the house visitor recorded in the visitors' book at the Radcliffe Infirmary that a patient who had been asked if the apothecary did his duty had declined to answer the question. ${ }^{78}$ But Wilde, though grateful for the care he had received from the hospital, did pour out his condemnation of the member of staff who had caused his suffering, and it is likely that when the need was great enough one among the patients would, like Wilde, find the resolution required, and action would follow; for although the eighteenth-century complaints procedure was clearly at its most effective in dealing with the misdemeanours of patients (and in this it differs from modern hospital procedures) there is ample evidence that the trustees strove to make it equally effective in dealing with any betrayal of trust by members of staff.

There is also ample evidence that contemporary opinion considered the process of value, and that the involvement of trustees in visiting and in coming into direct contact with patients was thought to be a protection against abuse. When, in 1814, the scandal of the cruelty and ill-treatment meted out to the patients at the York Asylum came to light, the reforms instituted included a requirement that two of the governors should visit the asylum each month, with - and this was a novel innovation - three ladies being asked to undertake the visitation of the female wards. ${ }^{9}$ In the Gentleman's

\footnotetext{
${ }^{76}$ The eighteenth annual report of the state of the General Infirmary at Kingston-upon-Hull, Hull, printed by Robert Peck in Scale Lane, 1801, p. 1.

"Wilde, op. cit., note 1 above, Book 311 . 178-181.

${ }^{78}$ Alexander George Gibson, The Radcliffe Infirmary, London, Oxford University Press, 1926, p. 75.

7 Kathleen Jones, Lunacy, law and conscience 1744-1845, London, Routledge \& Kegan Paul, 1955, pp. 80-92.
} 


\section{Complaints and complaint procedures in the eighteenth-and early nineteenth-century provincial hospitals in England}

Magazine in 1763 an article "humbly offered to the Consideration of Parliament" drew attention to the evils of the private madhouse, and in doing so pointed to the marked contrast between the "public hospitals, which are public benefits" and the private madhouses. In the public hospitals no person could be admitted as a patient "unless the party undergoes the inspection of discerning and impartial governors; and if any person under such examination is found a lunatic, and admitted, the case is reported weekly, and the best means used for a speedy recovery, that the patient may again become useful to the community. But in private Mad houses the very contrary is the case in all these instances". The intervention of the lay governor was seen as a protection against abuse of the sick. ${ }^{80}$ When the House of Recovery was established at Manchester in 1796 one of the regulations governing its function laid down that "the Committee of the Strangers Friend Society shall be requested to undertake the office of inspecting the House of Recovery", even though - because of the infectious nature of the cases treated in the hospital - all other visitors were to be prohibited. ${ }^{81}$ Gibson, writing his history of the Radcliffe Infirmary at a time when house visitors were still operative in many of the provincial voluntary hospitals, considered that they performed a "very useful function" even if they only discovered small abuses; their very presence in the hospital acted as a deterrent to all forms of corruption..$^{82}$

It was, of course, always possible that some ill-usage might escape detection for a while - it still does today - but the great interest of local committees in their own hospital, and the devotion which so many men displayed to their self-appointed task of succouring the weak, and helping the needy, ensured that before long the evil would be corrected. The persistence of Geoffrey Higgins exposed the irregularities in the York Asylum, and John Howard, almost single-handed, attempted the reform of the whole prison system. In doing so, he promoted an increasing awareness of the need to ensure clean and well-ventilated buildings for all kinds of purposes, including the care of the sick, and the need to control those men and women who exercised absolute power over their fellows. Howard visited the hospitals as he visited the prisons, disease and infection being problems common to them both, and published in his two great books - the first in 1777, the second in 1789 - accounts of what he found. In his work on the prisons Howard "revealed to the world a mass of maladministration and atrocious cruelty which made a deep and lasting impression", ${ }^{83}$ and that effect rubbed off upon the hospitals he studied at the same time, and in which he found defects. Not all hospitals were condemned. The Infirmary at Leeds "was one of the best hospitals in the kingdom", and the Norfolk and Norwich Hospital neat and clean "with a notable matron". The County Infirmary at Stafford was quiet and clean with "a humane and attentive apothecary", but the Radcliffe Infirmary was close and offensive, and in the Infirmary at Worcester there was not a window open, the wards were offensive, the

\footnotetext{
${ }^{80}$ Gentleman's Mag., January 1763, p. 25.

81 Thomas Bernard, 'Extract from the account of the House of Recovery established by the Board of Health at Manchester' in The reports of the society for bettering the condition and increasing the comfort of the poor, London, printed for the Society by W. Bulmer, 1798, pp. 74-75.

${ }^{82}$ Gibson, op. cit., note 78 above, p. 75.

${ }^{3}$ William Edward Hartpole Lecky, $A$ history of England in the eighteenth century, London, Longmans Green, 1892, 7 vols., vol. 7, p. 327.
} 


\section{W. B. Howie}

beds not made at noon, and the floors unwashed. At the Salop Infirmary the ceilings were low, the water closets offensive, and the building in need of repairs. ${ }^{84}$

Such unwelcome publicity made the trustees keenly aware of the need to be increasingly vigilant in their supervision of the nurses and domestics, and it is perhaps significant that about the time of Howard's visit the house visitors and the medical staff in Salop began to complain more actively of the lack of ventilation in the wards, of the windows of the wards being closed, and of the offensive state of the "vaults" adjoining the men's ward.85 In March 1788, three of the trustees complained to the Weekly Board that the men's ward "was uncommonly dirty and offensive; the Scullery and vault more particularly so, the Seat and Walls of the latter being besmeared with Filth of the most disgusting kind". The nurse was severely reprimanded for her "shameful neglect of duty", and narrowly escaped dismissal. She was ordered to report any patients spitting about the floor or walls, or indulging "in any other filthy Practice she finds them prone to", to the house visitor, a direction reinforced by calling the apothecary into the board meeting and ordering him to ensure that these directions were observed by the nurse, and that he, too, exercised greater control over the patients. ${ }^{86}$ Thereafter, close watch was kept on the state of the wards, and new building undertaken to remove the worst features of those that were unsatisfactory.

These reactions of the Salop Board were an example of the hospital trustees' extreme sensitivity to public criticism. To avoid such criticism it was necessary to try to have as effective a system for investigating complaints as possible, in order to detect all forms of abuse as they occurred, and to rectify them. There was every stimulus to do so. The charity had to have a reputation for being humane and caring in outlook, as well as being efficient in management, if it was to attract the necessary financial support. The poorer sections of the community had also to be reassured that if, through ill fortune, they became patients of the hospitals they would not become subject to any form of ill-treatment. Among the poor there was some suspicion that they might be subject to experimentation in hospital; as late as 1774 a speaker at the anniversary meeting of the Leicester Infirmary felt compelled to deny that it was so. ${ }^{87}$ Any tale of ill-treatment would add fuel to these rumours, particularly if it could be associated with the idea of experimentation - and the telling of it in the countryside, or to the justices when they visited the workhouse, could result in the withholding of subscriptions. That threat was a great deterrent in the eighteenth century, as great as the fear of civil action and punitive damages in the twentieth century, for without generous subscriptions, benefactions, and bequests, the whole work of the charity came to an end. The standing of the hospital in its community was the keystone to its survival.

\footnotetext{
4 John Howard, An account of the principal lazarettos in Europe with various papers relative to the plague: together with further observations on some foreign prisons and hospitals and additional remarks on the present state of those in Great Britain and Ireland, Warrington, William Ayres, 1789, pp. 192, 154, 174, $170,123,175$.

ss Minutes of Adjourned General Board of the Salop Infirmary, 25 August 1787.

" Minutes of Salop Weekly Board, 15 March 1788.

${ }^{87}$ John Nichols. The history and antiquities of the County of Leicester, London, Nichols, Son \& Bentley, 1815, 2 vols., vol. 1, p. 523.
} 